Available online at https://jurnal.stmikroyal.ac.id/index.php/jurdimas

\title{
SOSIALISASI PEMANFAATAN TEKNOLOGI INFORMASI INTERNET BERBASIS MEDIA SOSIAL SEBAGAI USAHA DAN TRANSAKSI
}

\author{
Yusli Yenni ${ }^{*}$, Intan Utnasari ${ }^{2}$ Mega Rahmawati $^{1}$ \\ ${ }^{1}$ Program Studi Teknik Informatika, \\ ${ }^{2}$ Sistem Informasi Universitas Putera Batam \\ Jalan R. Soeprapto, Muka Kuning, Kibing, Batu Aji, Kota Batam, Kepulauan Riau 29434 \\ email: *yusliany10@gmail.com
}

\begin{abstract}
Information technology era requires speed and processing to obtain information. Users are required to quickly obtain and process information as needed. The use of the internet covers many fields of education but the use of the internet also covers the scope of business and transactions. Development of internet technology is widely used in business and sales transactions. Because the internet can create new entrepreneurs. Internet-based social media is an application service that is widely used as a means for the purpose of publishing a service or product. In the implementation of the service, the pre-test method was used which was given to the mothers of the village of RT $03 \mathrm{RW} 01$ by giving a questionnaire to measure their understanding of social media. Furthermore, given the delivery of material on understanding social media and the internet. The next method is carried out in practice to implement it. This will provide benefits in understanding social media and the internet for business ventures, both businesses that are established individually or in groups. Because social media can be used as a promotional media, see market developments, provide experiences for consumers and serve as social media for competitors. The results obtained from this service, the community / village mothers have business facilities, namely using the social media Facebook. With this media, the native mothers of the village can promote or sell their products there..
\end{abstract}

Keywords: internet; social media; transactions

\begin{abstract}
Abstrak: Era teknologi informasi memerlukan kecepatan dan pemrosesan untuk mendapatkan informasi. Pengguna dituntut untuk lebih cepat memperoleh dan mengolah informasi sesuai kebutuhan. Penggunaan internet mencangkup banyak bidang pendidikan tetapi penggunaan internet juga mencangkup lingkup bidang usaha dan transaksi.Perkembagan teknologi internet banyak digunakan dalam bidang usaha dan transaksi penjualan. Kerena internet bisa menciptakan para enterpreneur yang baru. Internet berbasis media sosial merupakan suatu layanan aplikasi yang banyak dimanfaatkan sebagai sarana untuk tujuan mempublikasikan suatu jasa atau produk. Dalam pelaksanaan pengabdian digunakan metode pra test yang diberikan kepada ibu-ibu tiban kampung RT 03 RW 01 dengan memberikan koesioner untuk mengukur pemahaman tentang media social. Selanjutnya diberikan penyampaian materi tentang pemahaman media social dan internet. Metode selanjutnya di lakukan pelaksaan prakterk untuk mengimplemantasikannya. Hal ini akan memberikan pemanfaatand dalam pemahaman media social dan internet untuk usaha bisnis, baik usaha yang didirikan secara individual maupun kelompok. Karena media sosial dapat dijadikan suatu media promosi, melihat perkembangan pasar, memberikan pengalaman bagi konsumen dan sebagai media sosial kompetitor. Hasil yang didapat dari pengabdian ini, masyarakat/ibu-ibu tiban kampung mempunyai sarana usaha yaitu menggunakan media sosial facebook. Dengan media tersebut ibu-ibu tiban kampung dapat mempromosikan atau menjual produknya di sana.
\end{abstract}

Kata kunci : media sosia; internet; transaksi 
Available online at https://jurnal.stmikroyal.ac.id/index.php/jurdimas

\section{PENDAHULUAN}

Perkembangan teknologi saat ini banyak memberikan perubahan yang terjadi dalam bidang teknologi komunikasi. Perkembangan tersebut memberikan perubahan yang sangat besar dikalangan masyarakat. Teknologi yang berkembang saat ini mampu menciptaka alat komunikasi yang dapat mempermudah berkomunikasi dengan yang lainnya. Perkembangan teknologi informasi komunikasi memberikan dampak yang positif guna meningkatkan aktifitas masyarakat baik dalam bidangnya. Banyaknya sumber informasi yang tersedia melalui media online memberikan dukungan bisnis terhadap para pengusaha pengrajin dunia industri kecil (Mahedy, 2016)

$$
\text { Pemanfaatan teknologi }
$$

informasi komunikasi dalam bidang usaha yaitu memanfaatkan internet sebagai sarana usaha. Karena manfaat internet tidak hanya dari kalangan pemerintah saja tetapi juga merambah dalam bidang dunia usaha. Salah satu pemanfaatan internet dalam usaha digital marketing. Digital marketing merupakan suatu kegiatan dalam mempromosikan serta pencarian barang melalui media digital secara online dengan memanfaatkan sarana seperti sarana jaringan sosial (Purwana, 2017). Oleh karena itu dengan adanya internet dapat membuat para pelaku usaha dapat dengan mudah memasarkan produknya serta mampu di jangkau oleh konsumen dengan cepat dan tepat. Penggunaan internet dengan baik dan benar dapat mendorong para masyarakat menjadi pebisnis baik secara individual maupun kelompok

Penggunaan internet untuk dunia usaha dapat meningkatkan kesejahteraan ekonomi dalam masyarakat.
Memanfaatkan internet dalam media sosial dapat memberikan bantuan khususnya kepada ibu-ibu untuk dapat menjadi pelaku bisnis. Kerena pemanfaatan internet dalam media sosial dapat memberikan fasilitas bagi para ibu-ibu yang ingin menjadi enterpreneur. Karena sarana internet untuk dapat berinteraksi dengan banyak orang melalui jejaringan media sosial. Jejaring sosial diartikan sebagai sebuah sistem terstruktur sosial yang terdiri dari elemen-elemen individu atau organisasi (Febrilia, Nasution, \& Handarini, 2017). Ada kalanya teknologi sangat mendukung semua aktifitas baik diluar ataupun di dalam rumah, tetapi terkadang juga teknologi bisa menghancurkan hidup manusia jika tidak tau bagaimana memanfaatkannya. Tak banyak dari kita sebagai masyarakat yang mengerti akan teknologi sehingga mudah terpengaruh oleh konten-konten yang ada baik itu konten-konten positif dan negative.

Pengaruh konten negatif sudah sering diberitakan di berbagai media berupa pemuatan gambar porno, perjudian, penipuan, pelecehan, pencemaran nama baik dan berita bohong. Selain itu penggunaan jejaring sosial juga memiliki dampak negatif, salah satunya adalah cyberbullying yang biasanya menimpa anak-anak dan sesama remaja. Bahkan kejahatan dunia maya yang dikenal sebagai cybercrime sudah sampai pada peretasan situs-situs penting dalam negeri.

Untuk menghindari kejahatan di dunia maya, selalu ditekankan prinsip dasar yang harus diketahui dalam menggunakan internet. Prinsip dasar di dunia nyata berlaku pula di dunia maya. Penggunaan internet secara sehat dan aman perlu ditanamkan melalui pembelajaran etika berinternet secara 
Available online at https://jurnal.stmikroyal.ac.id/index.php/jurdimas

sehat (cyber ethics). Hal ini perlu disampaikan untuk menghindari kebiasaan jelek di dunia nyata akan terbawa di dunia maya dan menimbulkan kembali efek negatif di dunia nyata agar mampu melakukan edukasi pengelolaan keuangan kepada masyarakat.

Pembinaan ini dilakukan pada kawasan Tiban Kampung RT 03 RW 01 yang di peruntukkan buat ibu-ibu yang ada disana. Kegiatan pengabdian ini akan dilakukan dengan anggota ibu-ibu rumah tangga. Dengan kondisi ekonomi yang menegah kebawah ibu-ibu Tiban Kampung RT 03 RW 02 mengharapkan dapat membantu menambah pemasukkan keuangan keluarga. Namun ratarata tidak memiliki modal dan keterampilan khusus. Ibu-ibu Tiban Kampung RT 03 RW 02 hanya memiliki keahlian standar seperti memasak, menjahit, dan lainnya serta kelebihan waktu luang. Berdasarkan dari kondisi tersebut maka perlu adanya kegiatan sosialisasi dan pelatihan dalam memanfaatkan teknologi informasi internet berbasis jaringan media sosial agar bisa menjadi sarana dalam melakukan bisnis jual beli bagi masyarakat. Sehingga dapat dimanfaatkan untuk memulai kegiatan bisnis baik itu bisnis makanan maupun kerajinan. Sehingga ibu-ibu Tiban Kampung mempunyai fasilitas untuk mempromosikan produk bisnis.

\section{METODE}

Pelaksanaan pengabdian masyarakat dilakukan dengan jumlah responden 20 orang yang terdiri dari ibu-ibu Tiban Kampung RT 03 RW 01 dalam pemanfaatan internet dengan jejaringan media sosial sebagai sarana usaha dan transaksi bagi ibu-ibu. Kegiatan pengabdian pembinaan ini akan disertai dengan kegiatan praktek yaitu untuk para peserta agar mampu menggunakan internet dalam jejaringan sosial dalam membuka usaha baik secara individual maupun kelompok serta mampun mengelola transaksi secara online. Kegiatan ini juga akan menjelaskan bagaimana informasi yang akan terjadi.

\section{PEMBAHASAN}

Proses dalam pelaksanaan kegiatan pembina ini dimulai dengan memberikan kuesioner Pra Test untuk mengukur seberapa besar pengatahui ibu-ibu disana tentang teknologi internet pada jejaringan sosial yang dapat membantu ke dalam kegiatan usaha dan transaksi.

Setelah hasil dari Pra Tes di dapatkan maka pemateri mengarahkan dan memberikan pemahaman tentang internet pada jejaringan sosial dan pengetahuan perkembangan teknologi informasi dalam berbagai aktifitas sehingga dapat meningkatkan pengetahuan dan kemampuan dari para peserta bagaimana memanfaatkan internet pada jejaringan media sosial sebagai sarana usaha dan transaksi.

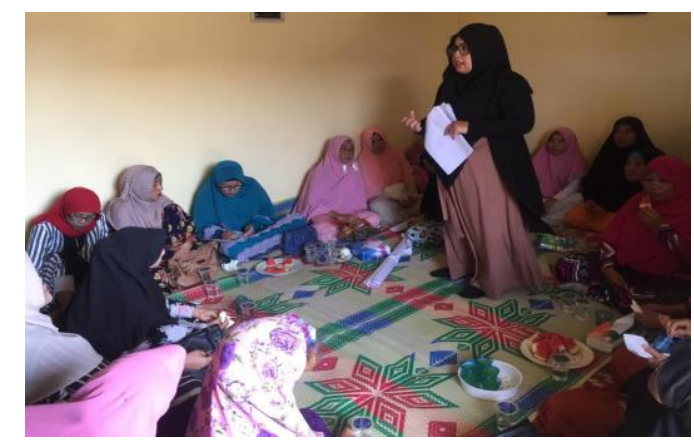

Gambar 1 Penyampaian Materi Pelaksana I 
Available online at https://jurnal.stmikroyal.ac.id/index.php/jurdimas

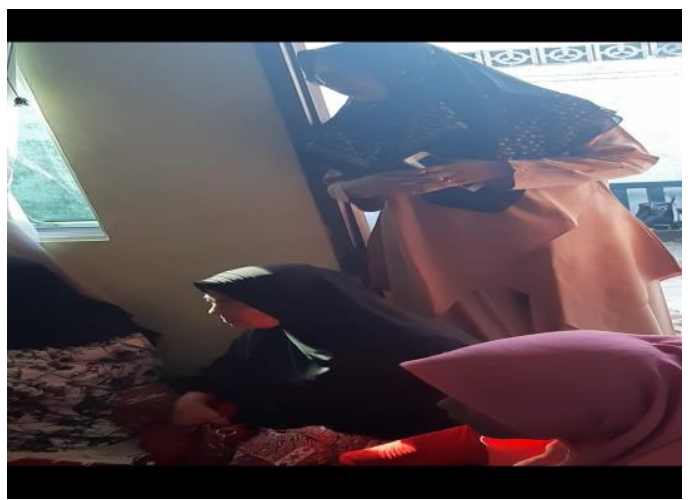

Gambar 2 Penyampaian Materi pelaksana II

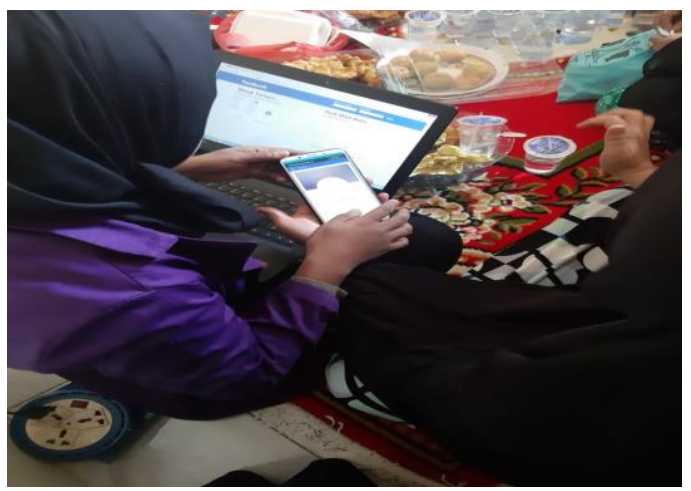

Gambar 3 Pratek pelaksanaan

\section{Evaluasi Pelaksanaan Kegiatan}

Kegiatan pengabdian ini akan di evaluasi dalam pelaksanaan kegiatan pemanfaatan internet jejaringan media sosial sebagai sarana usaha dan transaksi bagi ibu-ibu Tiban Kampung RT 03 dan RW 01 dapat di lihat dari hasil perbandingan antara kuesioner Pra Test yang diberikan pada hari pertama yang dilaksanakan sebelum kegiatan penyampaian materi yang akan di bandingkan dengan hasil praktek pada pelatihan yang kedua. Pelaksanaan paktek yang di adakan pada pertemuan kedua diharapkan para peserta dapat mamaksimalkan pemanfaatan internet pada jejaringan sosial sebagai usaha dan transaksi elektronik.

Berdasarkan pembinaan yang telah dilakukan pada masyarakat Tiban Kampung telah dapat memberikan dampak yang positif kepada para peserta dan juga kepada tim dosen yang melakukan pembinaan, secara lebih rinci hasil yang dicapai dari pelaksanaan pembinaan tersebut dapat diuraikan antara lain sebagai berikut:

1. Terjalinnya kerjasama antara Universistas Putera Batam dengan masyarakat Tiban Kampung secara berkelanjutan.

2. Peserta diberikan pembinaan mengenai manfaat penggunaan internet dalam kehidupan seharihari yang bisa dimanfaatkan sebagai media usaha dan transaksi dengan menggunakan media sosial.

3. Menambah wawasan masyarakat tentang penggunaan internet dan media sosial.

4. Mengembangkan dan berbagi ilmu pengetahuan kepada masyarakat yang ada, khususnya masyarakat Tiban Kampung.

Kegiatan pengabdian yang dilaksanakan di Tiban Kampung memberikan respon positif dan dapat diterima dengan baik oleh ibu-ibu. Ibuibu antusias mengikuti kegiatan pembinaan yang pengabdi lakukan. Dengan dilaksanakannya kegiatan pembinaan ini, pemahaman ibu-ibu semakin bertambah dan semakin bersemangat dalam menggunakan dan memanfaatkan fasilitas internet dan bersemangat memasarkan hasil usaha secara luas melalui penggunaan media sosial. Ibu-ibu sebagian besar telah memiliki smartphone dan telah memahami bahwa dengan smartphone yang mereka miliki dapat digunakan untuk membuat media sosial dan Toko Online yang dapat dijadikan alat promosi bagi produk yang telah dibuat. Sehingga dapat menjangkau konsumen yang lebih luas lagi untuk memperbaiki ekonomi keluarga. 


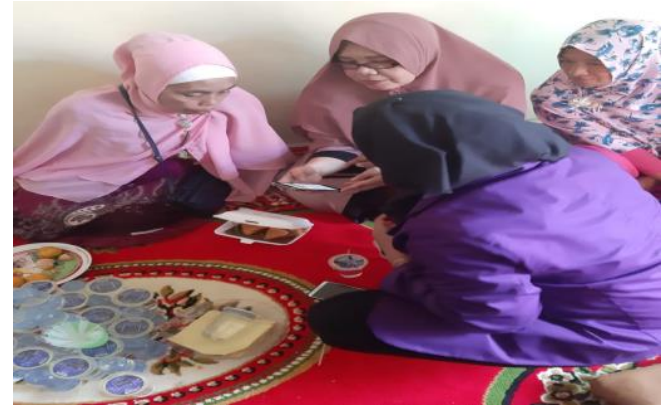

Gambar 4. Evaluasi kegiatan

Setelah pengabdian terlaksana, dapat disimpulkan bahwa ibu-ibu Tiban Kampung mulai berpikir untuk memajukan usaha dengan memanfaatkan jejaring sosial. Ide-ide kreatifpun semakin berkembang dengan bantuan dari internet. Dari hasil pengadian ini, tercipta sebuah group online dimana bisa dimaanfaatkan beramai-ramai untuk transaksi jual beli seTiban Kampung.

\section{SIMPULAN}

Hasil pengabdian ini dalam pembinaan dapat di berikan kepada ibuibu tiban kampung dalam memahami mengenai manfaat internet dan penggunaan pada jejaringan media sosial. Peserta pengabdian mampu menggunakan media sosial sebagai media usaha dan transaksi terkait dengan materi pengabdian yang telah diberikan.

\section{DAFTAR PUSTAKA}

Abdillah, R., Joyoatmojo, S., \& Noviani, L. (2017). PEMANFAATAN BLOG SEBAGAI MEDIA PEMBELAJARAN DALAM MENINGKATKAN PRESTASI BELAJAR SISWA.
Aulia, R., Mardalius, M., \& Dristyan, F. (2019). PENINGKATAN PEMANFATAN PERAN TEKNOLOGI INFORMASI BAGI PESERTA DIDIK LKP BINTANG

BATUBARA. JURDIMAS ROYAL, 2(1), 49-52.

Febrilia, I., Nasution, H., \& Handarini, D. (2017). PELATIHAN PENGGUNAAN JEJARING SOSIAL INSTAGRAM

DALAM MEMASARKAN

BARANG PADA IBU-IBU PKK DI KELURAHAN, 14(02), 108-113.

Mahedy, K. S. (2016). PELATIHAN PEMANFAATAN MEDIA ONLINE SEBAGAI SARANA PEMASARAN HASIL PRODUKSI BAGI ASOSIASI PENGRAJIN INDUSTRI KECIL ( APIK ) KABUPATEN, 389-398.

Nasution, D., Rahayu, E., \& Rohminatin, R. (2019). INTERNET SEHAT DAN AMAN (INSAN). JURDIMAS ROYAL, 2(2), 179-182.

Purwana, dedy. dkk. (2017). PEMANFAATAN DIGITAL MARKETING BAGI USAHA MIKRO , KECIL , DAN MENENGAH ( UMKM ), l(1), $1-17$.

Putriyandari, R., Amran, A., Roisah, R., Komalasari, Y., \& Yuliyana, W. (2018). Implementasi Pemanfaatan Media Sosial dalam Meningkatkan Pendapatan di Lembaga Belajar SMART CLUB BANDUNG, 1(1), 65-75.

Syahputra, A. K., Kurniawan, E., \& Nofriadi, N. (2019). PEMANFAATAN MEDIA 
Jurdimas (Jurnal Pengabdian Kepada Masyarakat) Royal

Vol. 4 No. 1, Januari 2021, hlm. 1-6

ISSN 2614-7912 (Print)

DOI: https://doi.org/10.33330/jurdimas.v4i1.543

ISSN 2622-3813 (Online)

Available online at https://jurnal.stmikroyal.ac.id/index.php/jurdimas

SOSIAL SEBAGAI MEDIA
INFORMASI
PUSKESMAS
PORSEA. JURDIMAS
ROYAL, 2(2), 115-120.
$\quad$ Y., \& Simatupang, J.

PEMANFAATAN INTERNET

SEBAGAI SUMBER

PEMBELAJARAN DAN

KEMANDIRIAN BELAJARAN

BAGI ANAK TIBAN LAMA.

Yenni, Y., \& Simatupang, J. 